\title{
Persistence of Anti-SARS-CoV-2 IgM Antibody up to 8 Months Post-COVID-19
}

\author{
Carlos David A. Bichara1,2,3, Ednelza S. G. Amoras1, Gergiane L. Vaz², Cléa N. C. Bichara3, \\ Isabella P. C. Amaral2, Antonio C. R. Vallinoto1,4 \\ ${ }^{1}$ Laboratório de Virologia, Instituto de Ciências Biológicas, Universidade Federal do Pará (UFPA), Belém, Brasil \\ ${ }^{2}$ Amaral Costa Medicina Diagnóstica, Belém, Brasil \\ ${ }^{3}$ Faculdade de Medicina, Centro de Ciências Biológicas e da Saúde, Universidade do Estado do Pará (UEPA), Belém, Brasil \\ ${ }^{4}$ Programa de Pós-Graduação em Biologia de Agentes Infecciosos e Parasitários, Instituto de Ciências Biológicas, Universidade \\ Federal do Pará (UFPA), Belém, Brasil \\ Email: vallinoto@ufpa.br
}

How to cite this paper: Bichara, C.D.A., Amoras, E.S.G., Vaz, G.L., Bichara, C.N.C., Amaral, I.P.C. and Vallinoto, A.C.R. (2021) Persistence of Anti-SARS-CoV-2 IgM Antibody up to 8 Months Post-COVID-19. Case Reports in Clinical Medicine, 10, 227-231. https://doi.org/10.4236/crcm.2021.109029

Received: August 3, 2021

Accepted: August 28, 2021

Published: August 31, 2021

Copyright (c) 2021 by author(s) and Scientific Research Publishing Inc. This work is licensed under the Creative Commons Attribution International License (CC BY 4.0).

http://creativecommons.org/licenses/by/4.0/

\begin{abstract}
Here, we present a longitudinal analysis of two patients who recovered from COVID-19 more than 8 months prior but showed persistent serological detection of anti-SARS-CoV-2 IgM. We still do not know the exact reason for this prolonged persistence of IgM in these patients. To our knowledge, these are the first reports of IgM persistence in the context of SARS-CoV-2 infection and point to the need for no longer using IgM as a diagnostic criterion for acute or recent COVID-19. One should opt for gold standard molecular methodologies due to their high sensitivity and specificity.
\end{abstract}

\section{Keywords}

COVID-19, SARS-CoV-2, Antibodies, IgM, Persistence

\section{Introduction}

Since November 2019, after the emergence of the novel coronavirus (severe acute respiratory syndrome coronavirus 2, SARS-CoV-2) in Wuhan, China [1], numerous studies have been published in an attempt to understand: 1) the epidemiology of infection [2], 2) the immunological aspects involved in combating the virus and the immunopathogenesis [3], 3) immunological and viral diagnostic markers [4] [5], 4) treatment possibilities [6], interactions of environmental factors in the context of virus transmissibility [7], and more recently, 5) the efficacy of vaccines approved for use [8].

Despite the large number of publications on COVID-19 (coronavirus disease 
2019) to date, many questions remain unanswered, and new information is generated every day, rendering the novel virus a continuous source of learning, especially in the context of the host immune response.

In recent study, Mallon et al. [9] reported that in subjects diagnosed with COVID-19, the IgM positivity was increased earlier, with the positivity peaking between days 32 and 38 post-onset of symptoms, but with a more rapid decline than the observed to IgG. Additionally, in a longitudinal study, Peghin et al. [10] observed IgM seroconversion in $90 \%$ of patients and its decline within 4 months. In our previous follow-up study, we reported a high frequency of loss of anti-SARS-CoV-2 IgG antibodies within 3 months after COVID-19 diagnosis in the Brazilian Amazon, but without information about IgM [11].

Here, we present laboratory results for two patients who recovered from COVID-19 more than 8 months prior with persistent serological detection of anti-SARS-CoV-2 IgM. This project was submitted to and approved by the $\mathrm{Hu}$ man Research Ethics Committee of the Institute of Health Sciences of the Federal University of Pará (CAAE: 31800720.1.0000.0018) in compliance with the guidelines and regulatory standards for research involving human beings. Both patients who agreed to participate in the study signed an informed consent form.

\section{Case Report}

\subsection{Patient \#1}

The first patient, a 47-year-old female residing in Belém, capital of the state of Pará (Brazil), underwent her initial serological evaluation on 05/26/2020 and showed reactivity against $\operatorname{IgM}(6.0 \mathrm{AU} / \mathrm{mL})$ and $\operatorname{IgG}(2.4 \mathrm{AU} / \mathrm{mL})$ by chemiluminescent microparticle immunoassay (MCIA) in an Alinity i automated system (Abbott Laboratories, Chicago, IL, USA) following the manufacturer's protocol. Two more analyses were performed on $06 / 04 / 2020$ and 12/28/2020, which showed IgM persistence at concentrations of $10.0 \mathrm{AU} / \mathrm{mL}$ and $5.3 \mathrm{AU} / \mathrm{mL}$, respectively. In response to a clinical-epidemiological inquiry, the patient reported having the following COVID-19-related symptoms: headache, runny nose, dry cough, sore throat, body pain, diarrhea, loss of smell and taste, fatigue and alopecia. She reported symptoms for four or more weeks and was treated with the following drugs: hydroxychloroquine, ivermectin, anti-inflammatory agents, antipyretic agents and amoxicillin.

\subsection{Patient \#2}

A second case of IgM persistence was monitored by our group to evaluate the clinical-epidemiological aspects. The patient, a 42-year-old male, had already undergone three serological evaluations by different methods (lateral immunochromatography and chemiluminescence). The first test was performed on 05/25/2020, showing seroreactivity against IgM and IgG by lateral immunochromatography (rapid test). The test was repeated on $12 / 15 / 2020$, again by immunochromatography, and showed reactivity against IgM and nonreactivity 
against IgG. After one week, on 12/23/2020, the patient underwent another test by chemiluminescence, and $\operatorname{IgM}$ persistence $(2.53 \mathrm{AU} / \mathrm{mL})$ and $\operatorname{IgG}$ absence were detected. In the last analysis, performed on $01 / 25 / 2021$, the reactivity to $\operatorname{IgM}(2.79 \mathrm{AU} / \mathrm{mL})$ was maintained.

\section{Discussion}

We still do not know the exact biological reason for this prolonged persistence of IgM in these patients. This phenomenon has been described following acute infection by hepatitis A virus (HAV) up to 60 days after patients recovered from the infection [12], in addition to other pathogens. Kapoor et al. [13] also reported the persistence of anti-West Nile virus IgM in cerebrospinal fluid samples from three patients at 110,141 and 199 days after acute central nervous system infection.

The titers of IgM and IgG anti-SARS-CoV-2 antibodies specific for the spike-binding receptor domain (RBD) decrease significantly, while IgA is less affected during infection resolution [14]. According to Isho et al. [15] anti-SARS-CoV-2 antibody responses were readily detected in serum and saliva, with maximum IgG levels reached between 16 and 30 days after symptom onset. A longitudinal analysis of the patients revealed that the anti-SARS-CoV-2 IgA and IgM antibodies declined rapidly, while the IgG antibodies remained relatively stable up to 105 days in both biological fluids.

To our knowledge, the cases presented herein are the first reports of IgM persistence in the context of SARS-CoV-2 infection and point to the need for no longer use IgM as a diagnostic criterion for acute or recent COVID-19.

The role of serological tests for the diagnosis of SARS-CoV-2 infection has been sufficiently debated and discouraged for diagnostic purposes and remains today as a limited tool for epidemiological observation. Especially IgM, is a biomarker related to a high false positive rate. In turn, the persistence of IgM antibodies for months to years is now a phenomenon recognized as frequent and without clinical significance, given the high sensitivity of current serological techniques; thus one should opt for gold standard molecular methodologies due to their high sensitivity and specificity.

\section{Conclusion}

The IgM persistence, as observed in the cases presented herein, should not be a criterion for singling out those who fit this profile and preventing them from performing their usual activities, as has been observed, because such actions can have negative socioeconomic and professional impacts on these individuals.

\section{Acknowledgements}

The authors gratefully thank both patients evaluated in the present study. This study was supported by the national council for scientific and technological development (CNPq Project; MCTIC/CNPq/FNDCT/MS/SCTIE/DECIT n. 
401235/2020-3) and Federal University of Pará (UFPA-PROPESP/PAPQ-2021).

\section{Conflicts of Interest}

The authors declare no conflicts of interest regarding the publication of this paper.

\section{References}

[1] World Health Organization. Coronavirus Disease (COVID-2019) Situation Reports; 2020 .

https://www.who.int/emergencies/diseases/novel-coronavirus-2019/situation-report

[2] Nouvellet, P., Bhatia, S., Cori, A., Ainslie, K.E.C., et al. (2021) Reduction in Mobility and COVID-19 Transmission. Nature Communication, 12, 1090.

[3] Bartsch, Y.C., Wang, C., Zohar, T., Fischinger, S., et al. (2021) Humoral Signatures of Protective and Pathological SARS-CoV-2 Infection in Children. Nature Medicine, 27, 454-462. https://doi.org/10.1038/s41591-021-01263-3

[4] Colagrossi, L., Antonello, M., Renica, S., Merli, M., et al. (2021) SARS-CoV-2 RNA in Plasma Samples of COVID-19 Affected Individuals: A Cross-Sectional Proof-ofConcept Study. BMC Infectious Diseases, 21, 184. https://doi.org/10.1186/s12879-021-05886-2

[5] Medina-Quero, K., Barreto-Rodriguez, O., Mendez-Rodriguez, V., Sanchez-Moncivais, A., et al. (2021) SARS-CoV-2 Infection: Understanding the Immune System Abnormalities to Get an Adequate Diagnosis. Bosnian Journal of Basic Medical Sciences. https://doi.org/10.17305/bjbms.2020.5400

[6] Kichloo, A., Albosta, M., Kumar, A., Aljadah, M., et al. (2021) Emerging Therapeutics in the Management of COVID-19. World Journal of Virology, 10, 1-29.

https://doi.org/10.5501/wjv.v10.i1.1

[7] Mecenas, P., Bastos, R.T.D.R.M., Vallinoto, A.C.R. and Normando, D. (2020) Effects of Temperature and Humidity on the Spread of COVID-19: A Systematic Review. PLoS ONE, 15, e0238339. https://doi.org/10.1371/journal.pone.0238339

[8] Teo, S.P. (2021) Review of COVID-19 Vaccines and Its Evidence in Older Adults. Annals of Geriatric Medicine and Research, 25, 4-9.

https://doi.org/10.4235/agmr.21.0011

[9] Mallon, P.W.G., Tinago, W., Leon, A.G., McCann, K., et al. (2021) All Ireland Infectious Diseases Cohort Study Group. Dynamic Change and Clinical Relevance of Post-Infectious SARS-CoV-2 Antibody Responses. Open Forum Infectious Diseases, 8, ofab122. https://doi.org/10.1093/ofid/ofab122

[10] Peghin, M., De Martino, M., Fabris, M., Palese, A., et al. (2021) The Fall in Antibody Response to SARS-CoV-2: A Longitudinal Study of Asymptomatic to Critically Ill Patients up to 10 Months after Recovery. Journal of Clinical Microbiology, 11, JCM0113821. https://doi.org/10.1128/JCM.01138-21

[11] Bichara, C.D.A., Amoras, E.S.G., Vaz, G.L., da Silva Torres, M.K., et al. (2021) Dynamics of Anti-SARS-CoV-2 IgG Antibodies Post-COVID-19 in a Brazilian Amazon Population. BMC Infectious Diseases, 21, 443.

https://doi.org/10.1186/s12879-021-06156-X

[12] Kao, H.W., Ashcavai, M. and Redeker, A.G. (1984) The Persistence of Hepatitis A IgM Antibody after Acute Clinical Hepatitis A. Hepatology, 4, 933-936.

https://doi.org/10.1002/hep.1840040525 
[13] Kapoor, H., Signs, K., Somsel, P., Downes, F.P., et al. (2004) Persistence of West Nile Virus (WNV) IgM Antibodies in Cerebrospinal Fluid from Patients with CNS Disease. Journal of Clinical Virology, 31, 289-291. https://doi.org/10.1016/j.jcv.2004.05.017

[14] Gaebler, C., Wang, Z., Lorenzi, J.C.C., Muecksch, F., et al. (2021) Evolution of Antibody Immunity to SARS-CoV-2. Nature, 591, 639-644.

https://doi.org/10.1038/s41586-021-03207-w

[15] Isho, B., Abe, K.T., Zuo, M., Jamal, A.J., et al. (2020) Persistence of Serum and Saliva Antibody Responses to SARS-CoV-2 Spike Antigens in COVID-19 Patients. Science Immunology, 5, eabe5511. https://doi.org/10.1126/sciimmunol.abe5511 